Pathophysiology of Haemostasis and Thrombosis
Pathophysiol Haemost Thromb 2003;33:59-63

DOI: $10.1159 / 000073847$
Received: April 25, 2002

Accepted after revision: April 7, 2003

\title{
A Prospective Controlled Study of a Computer-Assisted Acenocoumarol Dosage Program
}

\author{
Fernando Marco ${ }^{b}$ Carmen Sedano $^{a}$ Arancha Bermúdez ${ }^{a}$ \\ Mónica López-Duarte ${ }^{a}$ Elena Fernández-Fontecha ${ }^{a}$ Alberto Zubizarreta ${ }^{a}$ \\ a Servicio de Hematología del Hospital Universitario 'Marqués de Valdecilla', Universidad de Cantabria, Santander, \\ bServicio de Hematología, Hospital de Basurto, Bilbao, Spain
}

\section{Key Words}

Oral anticoagulants · Computer-assisted dosage . Therapeutic quality $\cdot$ Acenocoumarol $\cdot$ International normalised ratio

\begin{abstract}
The increase in oral anticoagulant (OA) treatment has led to development of new strategies for its control. We tested the efficacy of the GAO software (Dade Behring) in providing adequate acenocoumarol dosages for patients whose international normalised ratios (INRs) were no more than 0.5 points out of range. From December 1998 to August 1999, all outpatients in this setting were randomly assigned to receive computer-generated or traditionally fixed OA doses. Patients in their first 4 weeks of treatment were excluded. Overall, 8,352 dosages were calculated by the computer and 7,586 by the medical staff. The main endpoint of the study was the time spent in target INR range. The computer matched the traditional dosing, achieving a small but statistically significant greater efficacy in maintaining patients within the INR target range. The percentage of INR determinations over 5.5 was very low in both groups. Our results validate the computerised acenocoumarol dosing in our centre, achieving at least similar levels of effectiveness and safety compared with traditional dosage by medical staff.
\end{abstract}

$$
\text { Copyright } @ 2003 \text { S. Karger AG, Basel }
$$

\section{Introduction}

The number of patients who receive oral anticoagulants (OA) has dramatically increased in the last years as a result of the demonstration of their efficacy in several clinical conditions, particularly in atrial fibrillation $[1,2]$. It has been estimated that about 1 out of 200 persons is treated annually with OA in the United States and Europe [3]. Medical, nursing, technical and administrative staff in hospitals and anticoagulation clinics are becoming overwhelmed $[4,5]$. To deal with the increasing clinical and laboratory workload, several strategies have been advocated, such as improving the organisation of anticoagulation centres, referring patients back to general practitioners and encouraging patient self-monitoring and self-management of OA. However, it has been stated that only a minority of general practitioners are prepared to manage anticoagulation [6] and monitoring quality control of near-patient testing for patient self-monitoring may be difficult [1].

Computerised decision support systems (CDSS) have been applied to OA control and they help to reduce demands on medical and secretarial time in anticoagulation clinics. Besides, they may enable non-specialist clinicians or nurses to undertake AO control in primary care centres. Several programs have been developed to generate $\mathrm{AO}$ doses with good results [4, 7-10]. In a multicentre
Fernando Marco

Servicio de Hematología, Hospital de Basurto

Avenida Montevideo s/n. 48008 Bilbao (Spain)

Tel. +34 944006001, Fax +34944006188

E-Mailfmarco@telefonica.net 
Table 1. Patients' characteristics at every INR determination

\begin{tabular}{llr}
\hline & $\begin{array}{l}\text { Traditional } \\
\text { dosage group }\end{array}$ & $\begin{array}{l}\text { Computer } \\
\text { dosage group }\end{array}$ \\
\hline $\begin{array}{l}\text { Total } \\
\text { Sex }\end{array} \quad 7,586$ & 8,352 \\
$\quad$ Male & $4,243(56.0)$ & $4,651(55.8)$ \\
$\quad$ Female & $3,329(44.0)$ & $3,924(44.2)$ \\
Age & & \\
$\quad<50$ years old & $447(6.0)$ & $500(6.1)$ \\
$\quad 50-70$ years old & $3,183(42.6)$ & $3,440(42.0)$ \\
$\quad>70$ years old & $3,838(51.4)$ & $4,254(51.9)$ \\
Body weight & $1,263(19.9)$ & $1,352(19.7)$ \\
$\quad<60 \mathrm{~kg}$ & $3,220(50.8)$ & $3,517(51.2)$ \\
$\quad 60-80 \mathrm{~kg}$ & $1,859(29.3)$ & $2,001(29.1)$ \\
$\quad>80 \mathrm{~kg}$ & & \\
Dose & $4,138(54.5)$ & $4,428(53.0)$ \\
$\quad<15 \mathrm{mg} /$ week & $3,448(45.5)$ & $3,924(47.0)$ \\
$\quad>15 \mathrm{mg} /$ week & & \\
Therapeutic INR range & $5,199(68.5)$ & $5,774(69.1)$ \\
$\quad 2.0-3.0$ & $1,608(21.2)$ & $1,698(20.3)$ \\
$2.5-3.5$ & $779(10.3)$ & $880(10.5)$ \\
Other &
\end{tabular}

The results represent number of INRs with percentages shown in parentheses. Distribution by sex, age, body weight, dose and target INR range was similar in both treatment groups.

randomised study of 285 patients, a significant benefit was found in achieving target INR in the group of stable patients when doses were calculated by the computer [11]. To compare the efficacy and safety of computerised and traditional dosage by medical staff in maintaining patients within their therapeutic INR ranges, we have performed an 8-month prospective study on a population of 1,882 unselected patients, attempting to reproduce the experience in daily clinical practice.

\section{Patients and Methods}

All consecutive outpatients under OA treatment attending the anticoagulation unit of the Universitary Hospital 'Marqués de Valdecilla' in Santander, Spain, from December 1998 to August 1999 were enrolled in the study. Patients' characteristics are summarised in table 1. Individual target INR ranges were established by the responsible physician of each patient, according to the guidelines on oral anticoagulation $[1,2,12]$ and the patient's particular risk factors. All patients were treated with acenocoumarol as OA.

Patients were randomly assigned to receive computer-generated doses or traditionally fixed doses as they entered the study. Patients on the first 4 weeks of anticoagulation were excluded. At the midpoint of the study, all patients were switched to the alternative treatment. The GAO software (provided by Dade Behring) for anticoagu- lant therapy management was used in parallel with traditional dosing by experienced medical staff. This program calculates the dose of anticoagulant using a simple equation that increases or decreases the total weekly dose of anticoagulant by $1 \mathrm{mg}$ when the patient is underor over-anticoagulated and maintains the same dose when the therapeutic range is achieved. Time to next visit is established from a userdefined set of variables including current INR value, therapeutic range and the number of previous INRs within target range. Since this program does not calculate doses when the current INR value is more than 0.5 INR points out of the target range, all patients in this situation were excluded. The computer-generated instructions were always reviewed by a doctor before being passed to the patient. All clinicians participating in this study were haematologists with longterm experience in both manual and computerised OA dosage.

Patient's blood samples were taken by venepuncture and the INR was measured with a Sysmex CA-6000 optical density coagulometer. The International Sensitivity Index (ISI) of the thromboplastins used during the study was between 1.1 and 1.2. Our laboratory participates in the Spanish quality control program.

For every visit of every patient, current INR value, dose change, time to next visit and next visit INR value were recorded, and proportion of time within the therapeutic range was calculated, according to the method of Rosendaal et al. [13]. This analysis assumes a linear increase or decrease between two consecutive determinations and has demonstrated to be preferable to other methods [14]. Results of patients out of their programmed visits were not considered. Information about the clinical outcome of patients was not obtained in any case, since it was not the objective of the present study.

\section{Statistical Analysis}

The main endpoint of the study was the proportion of time spent in the target INR range. We analysed results by traditional or computerised dosage, and then by subgroups of sex, age, target INR range, body-weight, and weekly dose amount. All analyses were performed on an intention-to-treat basis (doses from the computer group that were corrected by doctors remained for analysis in the computer group). We tested the significance of differences between mean proportion of time in target INR range from each group with Student's $t$ test. We used the $\chi^{2}$ analysis for testing the significance of differences in proportion of determinations within target INR range. All statistical analyses were performed employing the NCSS statistical package.

\section{Results}

During the time of the study, 21,074 INR determinations were performed in our centre on outpatients attending for OA control. Overall, data from 16,145 visits of 1,882 randomised patients fitted the settings of the study and results from 15,938 visits could be analysed (fig. 1,2). OA dosage was performed by the computer and the medical staff in 8,352 and 7,586 controls, respectively. Results by dose groups are shown in table 2 . Time between visits was significantly longer in the traditional-dose group. Proportion of time in target range was slightly higher in the computer-dose group, the difference being statistically 


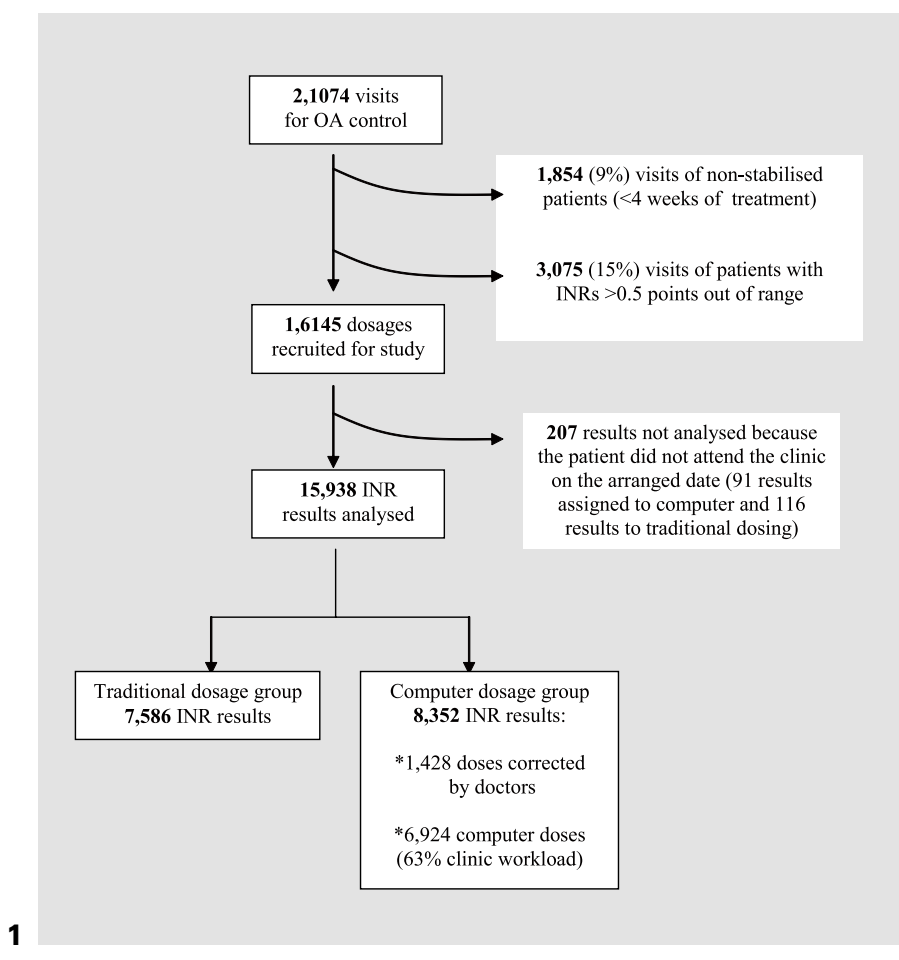

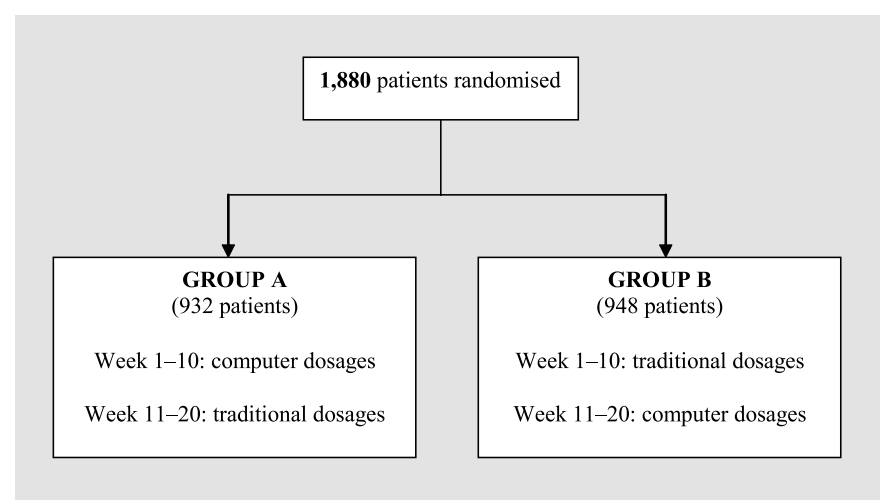

Fig. 1. Trial profile.

Fig. 2. Randomisation of patients to the arms of the study.
Table 2. Overall results for patients in the computer dosage and traditional dosage groups, and significance level of the differences between treatment groups

\begin{tabular}{llll}
\hline & $\begin{array}{l}\text { Traditional } \\
\text { dosage group }\end{array}$ & $\begin{array}{l}\text { Computer } \\
\text { dosage group }\end{array}$ & $\begin{array}{l}\text { Statistical } \\
\text { significance }\end{array}$ \\
\hline Number of INRs & 7,586 & 8,352 & \\
Time in range, \% & 65.5 & 67.3 & $\mathrm{p}<0.002$ \\
Time under range, \% & 22.8 & 21.1 & $\mathrm{p}<0.002$ \\
Time over range, \% & 11.7 & 11.6 & n.s. \\
Time INR $>$ 5.5, \% & 0.21 & 0.15 & n.s. \\
INRs in range, \% & 53.5 & 54.3 & n.s. \\
Low INRs, \% & 27.7 & 26.9 & n.s. \\
High INRs, \% & 18.9 & 18.8 & n.s. \\
INRs $>$ 5.5, \% & 0.8 & 0.7 & n.s. \\
Mean time between visits, days \pm SD & $21.2 \pm 27.7$ & $19 \pm 17.4$ & $\mathrm{p}<0.001$ \\
Maximum time between visits, days & 42 & 36 & \\
Mean INR & 2.44 & 2.46 & n.s. \\
Mean dose, mg/week \pm SD & $16 \pm 17.8$ & $16.2 \pm 17.7$ & n.s. \\
Dose changes, \% & 27.3 & 32.3 & $\mathrm{p}<0.001$ \\
Traditional interventions, \% & 100 & 17.1 & \\
\hline
\end{tabular}

n.s. $=$ Non-significant. significant. Patients who received doses calculated by doctors presented a greater risk to be under-treated, while over-anticoagulation occurred in almost identical proportions in both groups. The percentage of INR determinations superior to 5.5, which predicts a higher risk of bleeding, was very low in both groups.

Computerised vs. Manual Anticoagulant Dosage
The doctors prescribed 5\% less dose changes than the computer (table 2). About 17\% of instructions generated by the computer were corrected by the doctors, most changes affecting the time to next visit, not the dose. Overall, in the computer arm, $63 \%$ of the doses were finally provided by the program.

Pathophysiol Haemost Thromb 2003;33:59-63 
Table 3. Results obtained by the computer dosage group and the traditional dosage group in different subgroups of sex, age, body weight, dose and target INR range, and statistical significance of the differences between treatment groups

\begin{tabular}{|c|c|c|c|}
\hline & \multicolumn{2}{|c|}{ Time in range, $\%$} & \multirow{2}{*}{$\begin{array}{l}\text { Statistical } \\
\text { significance }\end{array}$} \\
\hline & $\begin{array}{l}\text { traditional } \\
\text { dosage group }\end{array}$ & $\begin{array}{l}\text { computer } \\
\text { dosage group }\end{array}$ & \\
\hline Total & 65.5 & 67.3 & $\mathrm{p}<0.002$ \\
\hline \multicolumn{4}{|l|}{ Sex } \\
\hline Male & 66.4 & 67.3 & n.s. \\
\hline Female & 64.2 & 67.2 & $\mathrm{p}<0.001$ \\
\hline \multicolumn{4}{|l|}{ Age } \\
\hline$<50$ years old & 59 & 60.8 & n.s. \\
\hline $50-70$ years old & 65.8 & 67.7 & $\mathrm{p}<0.002$ \\
\hline$>70$ years old & 67.3 & 66.8 & n.s. \\
\hline \multicolumn{4}{|l|}{ Body weight } \\
\hline$<60 \mathrm{~kg}$ & 66.1 & 67.9 & n.s. \\
\hline $60-80 \mathrm{~kg}$ & 66.0 & 68.1 & $\mathrm{p}<0.01$ \\
\hline$>80 \mathrm{~kg}$ & 64.4 & 67.5 & $\mathrm{p}<0.01$ \\
\hline \multicolumn{4}{|l|}{ Dose amount } \\
\hline$<15 \mathrm{mg} /$ week & 66.5 & 68.7 & $\mathrm{p}<0.01$ \\
\hline$>15 \mathrm{mg} /$ week & 64.2 & 65.7 & $\mathrm{p}<0.05$ \\
\hline \multicolumn{4}{|l|}{ Therapeutic INR range } \\
\hline $2.0-3.0$ & 67.6 & 69.3 & $\mathrm{p}<0.01$ \\
\hline $2.5-3.5$ & 64.8 & 66.3 & n.s. \\
\hline Other & 53 & 56 & n.s. \\
\hline
\end{tabular}

n.s. = non-significant.

In the analysis by subgroups of age, sex, body weight, dose and therapeutic range, computer-dosing showed a small benefit in achieving target INR range in many categories, reaching statistical significance in women and some age, body weight, dose and target INR range subgroups of patients (table 3 ).

\section{Discussion}

Although the efficacy of OA treatment has been unequivocally demonstrated for several indications, if the patients under anticoagulant treatment do not finally achieve the targeted intensity of anticoagulation, thromboembolic or bleeding complications may follow. In a large collaborative prospective study of complications of OA therapy $[15,16]$, the incidence of thrombotic events increased from 2.3 to $17.5 \%$ patient-years when INR was under 1.5. In an analogous way, the risk of bleeding was higher when INR exceeded 4.5 (an incidence of over $40 \%$ patient-years). However, control of OA therapy is often unsatisfactory and about one-third of the outpatients attending anticoagulant clinics remain poorly controlled. Several factors may account for unstable anticoagulant control, such as poor compliance [17], interactions with other drugs [18], dietary changes [19], and anticoagulant resistance [12]. The prescription of incorrect doses is another possible factor involved in poor anticoagulation control. Therapeutic monitoring of OA has traditionally been the consultant haematologist's role, but in the last years it has been increasingly devolved to the primary care setting, with the development of CDSS and local guidelines for OA management. Apart from their practical benefits, such as enabled easy therapeutic quality auditing, the CDSS may provide faster achievement of a stable dose in patients requiring institution of anticoagulation $[8,20]$, and it has been suggested by some studies that they maintain stable patients more time in target range $[7,8,10,11]$. In our study, the computer obtained slightly better results than the medical staff. We found that under-anticoagulation was more frequently observed in the traditional-dose group. As described in previous studies $[8,21]$, physicians are more cautious regarding over-treatment than under-anticoagulation, exposing patients to an excessive risk of thrombosis.

There is controversy about who should take care of monitoring chronic anticoagulation. Some authors claim that an anticoagulation clinic offers a real advantage to anticoagulated patients in terms of prevention of thromboembolic events and haemorrhagic complications [22]. Nevertheless, OA control has been undertaken by primary-care units, which utilise CDSS with excellent results in some studies [10, 23]. In our experience, the computer achieved at least as good results as medical staff, but it has to be considered that all CDSS instructions were reviewed by haematologists, and as much as $17.1 \%$ of them needed to be amended before being delivered to the patient. Most corrections were made by the doctors in order to change time between visits. As the software tended to schedule less time between visits than the medical staff, this could partially offset the saving of personal and material resources that a CDSS-based setting provides $[4,5,11]$. Overall, the computer was able to save about $63 \%$ of the clinic workload.

In the analysis of results from different subgroups of patients, we detected marginal benefits in anticoagulant control favouring the computer-dose group. Interestingly, the proportion of time in range never surpassed $70 \%$, even when considering the most favourable categories. Further improvement of OA control might be obtained through more intensive patient education, or the develop- 
ment of new anticoagulant drugs with a more favourable toxic/therapeutic ratio [24].

In conclusion, our study shows that computerised decision support systems for OA can be safe and effective, achieving similar levels of therapeutic quality to those obtained by experienced medical staff. However, as this is a single-centre study, the conclusions should not be generalised to other centres and different computer-assisted dosage programs.

\section{Acknowledgments}

We are indebted to María Antonia Nieto, Marisa Gandarillas, Encarna Martín and Conchita López Maza for their expert technical assistance.

\section{References}

1 British Society for Haematology: Guidelines on Oral Anticoagulation, ed 3. Br J Haematol 1998;101:374-387.

2 Hirsh J, Dalen JE, Anderson DR, Poller L, Bussey H, Ansell J, Deykin D: Oral anticoagulants. Mechanisms of action, clinical effectiveness and optimal therapeutic range (review). Chest 2001;119(suppl):8S-21S

3 Fihn SD, McDonell M, Martin D, Henikoff J, Vermes D, Kent D, White RH: Risk factors for complications of chronic anticoagulation. A multicenter study. Warfarin Optimised Outpatient Follow-up Study Group. Ann Intern Med 1993; 118:511-520.

4 Galloway MJ, Foggin JJ, Dixon S: Introduction of computer-assisted control of oral anticoagulation in general practice. J Clin Pathol 1995; 48:1144-1146.

5 Barbui T, Finazzi G, Remuzzi A: Clinical anticoagulation laboratory and oral anticoagulant therapy treatment. Instrumental and methodology. Thromb Haemost 1995;74:511-514.

6 Taylor F, Ramsay M, Covell B, Gaminara L, Thomson D, Cohen H, et al: Management of expanding anticoagulant clinics: A role for general practitioners? Br J Haematol 1994;86:68.

7 Poller L, Wright D, Rowlands M: Prospective comparative study of computer programs used for management of warfarin. J Clin Pathol 1993;46:299-303.

8 Vadher B, Patterson DLH, Leaning M: Evaluation of a decision support system for initiation and control of oral anticoagulation in a randomised trial. BMJ 1997;314:1252-1256.

9 Fitzmaurice DA, Hobbs FDR, Delaney BC, Wilson S, MacManus R: Review of computerised decision support systems for oral anticoagulation management. Br J Haematol 1998; 102:907-909
10 Fitzmaurice DA, Hobbs FD, Murray ET, Holder RL, Allan TF, Rose PE: Oral anticoagulation management in primary care with the use of computerized decision support and nearpatient testing: A randomized, controlled trial. Arch Intern Med 2000;160:2343-2348.

11 Poller L, Shiach CR, MacCallum PK, Johansen AM, Magalhaes A, Jespersen J: Multicentre randomised study of computerised anticoagulant dosage. Lancet 1998;352:1505-1509.

12 Palareti G: A guide to oral anticoagulant therapy. Italian Federation of Anticoagulation Clinics. Haemostasis 1998;28(suppl 1):1-46.

13 Rosendaal FR, Cannegieter SC, van der Meer FJM, Briët E: A method to determine the optimal intensity of oral anticoagulant therapy. Thromb Haemost 1993;69:236-239.

14 Hutten BA, Prins MH, Redekop WK, Tijssen JGP, Heisterkamp SH, Büller HR: Comparison of three methods to assess therapeutic quality control of treatment with vitamin $\mathrm{K}$ antagonists. Thromb Haemost 1999;82:1260-1263.

15 Palareti G, Leali N, Coccheri S, Poggi M, Manotti C, D'Angelo A, Pengo V, Erba N, Moia M, Ciavarella N, Devoto G, Berrettini M, Musolesi S, on behalf of the Italian Study on Complications of Oral Anticoagulant Therapy: Bleeding complications of oral anticoagulant treatment: An inception-cohort, prospective collaborative study (ISCOAT). Lancet 1996; 348:423-428.

16 Palareti G, Manotti C, D’Angelo A, Pengo V, Erba N, Moia M, Ciavarella N, Devoto G, Berrettini M, Leali N, Poggi M, Legnani C, Musolesi $\mathrm{S}$, Coccheri $\mathrm{S}$, on behalf of the ISCOAT Study Group (Italian Study on Complications of Oral Anticoagulant Therapy): Thrombotic events during oral anticoagulant treatment: Results of the inception-cohort, prospective, collaborative ISCOAT study. Thromb Haemost 1997;78:1438-1443.

17 Kumar S, Haigh JRM, Rhodes LE, Peaker S, Davies JA, Roberts BE, Feely MP: Poor compliance is a major factor in unstable outpatient control of anticoagulant therapy. Thromb Haemost 1989;62:729-732.
18 Wells PS, Holbrook AM, Crowther NR, Hirsh $\mathrm{J}$ : Interaction of warfarin with drugs and food. Ann Intern Med 1994;121:676-683.

19 Sorano GG, Biondi G, Conti M, Mameli G, Licheri D, Marongiu F: Controlled vitamin K content in diet for improving the management of poorly controlled anticoagulated patients: A clinical practice proposal. Haemostasis 1993; 23:77-82.

20 Manotti C, Quintavalla R, Pattacini C, Tagliaferri A, Pini M: Evaluation of a computerassisted dosage prediction method for oral anticoagulant therapy. Thromb Haemost 1997; Suppl 699.

21 Azar AJ, Deckers JW, Rosendaal FR, van Bergen PF, van der Meer FJM, Jonker JJC, Briëf $\mathrm{E}$ : Assessment of therapeutic quality control in a long-term anticoagulant trial in post-myocardial infarction patients. Thromb Haemost 1994;72:347-351.

22 Cortelazzo S, Finazzi G, Viero P, Galli M, Remuzzi A, Parenzan L, Barbui T: Thrombotic and hemorrhagic complications in patients with mechanical heart valve prosthesis attending an anticoagulation clinic. Thromb Haemost 1993;69:316-320.

23 Fitzmaurice DA, Hobbs FD, Murray ET: Primary care anticoagulant clinic management using computerised decision support and near patient International Normalised Ratio (INR) testing: Routine data from a practice nurse-led clinic. Fam Pract 1998;15:144-146.

24 Eriksson H, Eriksson UG, Frison L, Hansson PO, Held P, Holmström M, Hägg A, Jonsson T, Lapidus L, Leijd B, Stockelberg D, Säfwenberg U, Taghavi A, Thorsen M: Pharmacokinetics and pharmacodynamics of melagatran, a novel synthetic LMW thrombin inhibitor, in patients with acute DVT. Thromb Haemost 1999;81: 358-363. 